\title{
A patient with a diagnosed patent ductus arteriosus - what next?
}

\author{
Joanna Kukawczyńska-Noczyńska', Katarzyna Bortnowska², Elżbieta Kukawczyńska \\ 'Department of Pediatrics, Allergology and Cardiology, USK, Wroclaw, Poland \\ ${ }^{2}$ Wroclaw Medical University, Poland
}

\section{ABSTRACT}

Among congenital heart defects of the cardiovascular system, patent ductus arteriosus (PDA) comprises about $10 \%$ in the general population. Prematurity significantly raises the likelihood of PDA: in preemies of very low birth weight this defect appears with a frequency up to 65\%, and in extremely low birth weight preemies up to $80 \%$. Over a span of many years of research many different methods for treating PDA have been discovered, modified, and improved. Invasive treatment (thoracotomy, thoracoscopy, and percutaneous closure) as well as therapeutic strategies (symptomatic treatment, pharmacological treatment) allow for complete closure of PDA in every patient. The limitations of particular methods in regard to age and body mass of the child, their clinical state, as well as the morphology of the PDA itself, require careful analysis when choosing the appropriate treatment method based on the effectiveness and permanency of closing the duct as well as minimal invasiveness. Among preemies and newborns it is possible to close the PDA using symptomatic and pharmacological treatment as well as through thoracotomy and thoracoscopy, while in older children and adults the method of choice is the percutaneous closure of PDA. Matching the correct treatment strategy with the clinical situation is key to the successful closure of the duct. Presented in the text below is an overview of available methods and their usefulness in treating PDA.

\section{KEY WORDS:}

patent ductus arteriosus, pharmacological therapy, percutaneous closure, video-assisted thoracoscopy.

\section{CHARACTERISTICS OF THE DUCTUS ARTERIOSUS, METHODS AND POSSIBILITIES OF TREATMENT}

The ductus arteriosus (DA) is a vessel connecting the pulmonary trunk with the proximal section of the descending aorta, which allows blood to circumvent pulmonary circulation during foetal life. In normal circumstances after birth, with the newborn's first inspiration there is a sudden and significant drop in pulmonary resistance and a reversal of pressure gradient between the pulmonary trunk and the aorta, which in turn changes the flow of blood from the right-left direction present during in utero life to left-right. The increase in oxygen concentration in the newborn's blood initiates the secretion of endothelin from the vascular endothelium as well as the outflow of potassium ions from potassium channels, which results in the contraction of the smooth muscles of the vessel. The lungs of the newborn start to produce bradykinin, a natural vaso-constrictor [1]. A very important stage in the functional patent ductus arteriosus (PDA) closure is the decrease in PGE1 and PGE2 levels, which are called endogenous prostaglandins. PGE1 and PGE2 are produced by the lumen of the ductus to main-

\section{ADDRESS FOR CORRESPONDENCE:}

Joanna Kukawczyńska-Noczyńska, Lower Silesian Center for Heart Diseases Medinet, Kamieńskiego 73 A,

51-124 Wroclaw, Poland, e-mail: jo.ku@wp.pl 
tain ductus patency during pregnancy until birth [2]. The incidence of PDA at $80 \%$ in preterm infants with respiratory distress syndrome (RDS) may be related to the increased circulating PGE2 level associated with RDS. In this phase the functional closure of the DA occurs within the first 60 hours of life in the newborn $[1,3,4]$. In the subsequent days of life, local hypoxia of the muscle cells in the DA leads to their death and stimulates production of factors exciting endothelial proliferation, which successively leads to complete obliteration of the DA in $88 \%$ of newborns with proper circulatory function within eight weeks [1-6]. The decrease in the level of prostaglandins in newborn's blood increases vessel vasodilatation and allows the DA to close properly. The incidence of PDA at $80 \%$ in preterm infants with RDS may be related to the increased circulating PGE2 level associated with RDS [3-5].

What remains after a successful closure of the DA in the adult individual is the arterial ligament. A failure of the DA to spontaneously close during the newborn period is classified as a congenital heart defect of the cardiovascular system, which can occur as an isolated defect or as part of a compound defect or syndrome such as dextrotransposition of the great arteries (dTGA), coarctation of the aorta (CoA), hypoplastic left heart syndrome (HLHS), or tetralogy of Fallot (ToF).

Diagnosis of PDA can be achieved based on echocardiographic examination, and patients in which patent ductus arteriosus is diagnosed represent a wide cross section in terms of age.

\section{EPIDEMIOLOGY}

PDA occurs with a frequency of $0.7 \%$ in the general population. It constitutes 5 to $10 \%$ of all congenital heart defects of the cardiovascular system [5, 6]. Prematurity increases the likelihood of occurrence of PDA, and in preemies with very low birth weight (VLBW: 1000-1500 g) the frequency of symptomatic PDA is estimated at $30-65 \%[2,7-9]$, and in preemies with extremely low birth weight (ELBW below $1000 \mathrm{~g}$ ) up to as much as $70-80 \%[5,10,11]$. PDA occurs roughly $2-3$ times more frequently in female infants [1]. PDA also occurs more frequently in the presence of genetic syndromes associated with point mutations, autosomal chromosomal aberrations, and diseases linked with sex. PDA has also been observed in cases of infections with Rubella during pregnancy and in cases where the mother used drugs such as alcohol, amphetamine, or phenytoin $[2,5]$.

\section{PATHOPHYSIOLOGY}

In the patent ductus arteriosus blood flow occurs in accordance with the pressure gradient, from the aorta to the pulmonary trunk as a result of the higher pressure present in the aorta, and lower in the pulmonary trunk.
In extreme cases the volume of blood flow from the aorta to the pulmonary trunk can be as much as $70 \%$ of the ejection fraction of the left ventricle, leading to significant overload, a decrease in the volume of blood in peripheral circulation, and a decrease in pressure in the descending aorta and hypoperfusion of the abdominal organs, which contributes to impairment of renal function and hypoxia of peripheral tissues, symptomised by cyanosis or necrotising enterocolitis. Increased blood flow in pulmonary circulation results in respiratory disorders potentially leading to pulmonary oedema. Immaturity of the tunica media of the pulmonary arterioles and their decreased resistance additionally deepen the hypoperfusion of the lungs $[2,5,10,12]$. Long lasting left-right shunt inevitably leads to pulmonary hypertension, contributing to bleeding from the pulmonary vessels and bronchopulmonary dysplasia; as a result of these processes a reversal of the direction of the shunt to right-left occurs and irreversible changes in vascularisation of the lungs in the form of Eisenmenger's syndrome ensue [2].

\section{PRESENTATION OF PDA AND ITS CLINICAL CONSEQUENCES}

PDA most commonly occurs sinistrally (from the left pulmonary artery); however, in very rare cases it can also occur dextrally (from the right pulmonary artery) as well as bilaterally. Sinistral DA is a physiological structure that functions during proper foetal development. The presence of dextral DA is commonly connected with congenital defects of the aortic arch and/or pulmonary trunk [13]. The morphology of PDA is characterised by significant diversity; most commonly, however, it has a conical or funnel shape. The aortic end, called the ductal ampulla, is wide and narrows incrementally as it proceeds towards the pulmonary end, achieving its smallest diameter at the pulmonary end. The common descriptors of the duct, i.e. conical, tubular, short, or long, have been supplanted by a classification system introduced by Krichenko and used during angiographic examination of the duct [13].

Depending on the size of the PDA and diagnosed clinical symptoms, we can classify several types of PDA $[14,15]$ :

- silent PDA, with a diameter of $1.5 \mathrm{~mm}$ or less, characterised by absence of audible murmur or clinical symptoms; may be left open; some authors report an increased risk of endocarditis as an indication to close the PDA,

- very small PDA, diameter less than or equal to $1.5 \mathrm{~mm}$, characterised by an audible murmur but often without clinical symptoms. Closure of PDA is recommended because the benefits of closure outweigh the risks of the procedure,

- small PDA, diameter 1.5 to $3.0 \mathrm{~mm}$, with a present audible murmur and clinical symptoms of PDA also present. Closure of PDA is recommended, 
- medium PDA, diameter of 3.0 to $5.0 \mathrm{~mm}$ as well as large PDA, diameter of over $5.0 \mathrm{~mm}$ both with loud audible murmur and exacerbated symptoms of PDA. Closure of PDA recommended.

Patients with haemodynamically irrelevant PDA, so-called "small PDA" typically present asymptomatically or with only a quiet heart murmur. In these cases the PDA is often discovered incidentally in the process of echocardiographic examination for unrelated causes. The psychomotor development of children with "small PDA" proceeds properly; however, they may be predisposed to achieving slightly smaller gains in body mass in comparison to their contemporaries without PDA [16]. The main argument for closing silent and small PDAs is prophylaxis of later complications of PDA such as increased risk of endocarditis and aneurysm and risk of its dissection $[16,17]$. Routine closure of PDA is controversial and should only be considered in children of preschool or school age $[16,17]$.

Patients with haemodynamically significant PDA (hsPDA) can present various clinical symptoms. Because symptoms are not homogeneous and remain in strict correlation to the age of the child, we can only definitively diagnose hsPDA when we can observe at least two of the following symptoms: systolic or systolic-diastolic heart murmur, tachycardia, pulsus celer, systolic-diastolic amplitude in blood pressure measurements $>25 \mathrm{~mm} \mathrm{Hg}$, hepatomegaly, pulmonary haemorrhage, marked respiratory exertion, crackles in the lung fields, bloody expectorate in the respiratory tract, oliguria, failure to thrive, and intolerance or reduced tolerance to physical exertion [8, $9,16,18,19]$.

On chest X-ray we may observe an enlarged cardiac shadow with obliteration, enlargement of the left atrium, features of increased vascular visibility, and in extreme cases pulmonary oedema and emphysema.

EKG may be unremarkable during the newborn period and early infancy. In older infants and children we can diagnose left axis deviation, traits of left ventricular enlargement, as well as repolarisation disturbances over the left ventricle. According to source data, a partial block of the left branch of the bundle of Hiss was described in a portion of patients [16]. Echocardiography is the primary examination as well as the gold standard allowing for a definitive diagnosis of patent ductus arteriosus and allowing assessment of its haemodynamic significance.

The proposed echocardiographic traits of haemodynamically relevant PDA according to selected sources are as follows (presence of two of the three criteria listed below are confirmatory for PDA) [8]:

- smallest diameter $>1.4 \mathrm{~mm}$,

- PDA/RPA > 0.5 (parameter independent of body mass),

- relation of diameter of the left atrium to the diameter of the aorta above 1.5 ,

- depth of the influx wave from the PDA to the pulmonary trunk.
Additional parameters such as symptoms of overload of the left ventricle, rate of end diastolic flow in the left pulmonary artery above $0.4 \mathrm{~m} / \mathrm{s}$, as well as rate of regurgitation flow in the aorta in the diastolic phase below the PDA egress, can also be used in qualification of the relevance of PDA.

\section{PROCEDURE IN CASE OF PATENT DUCTUS ARTERIOSUS}

Over many years of clinical experience many methods allowing for the closure of PDA have been discovered, modified, and improved. Presented and discussed below are current possible methods for obliteration of PDA.

\section{SYMPTOMATIC TREATMENT}

On the basis of randomised, controlled trials conducted in the 1980s two different methods can be identified useful in cases of mild symptoms of PDA. They are: symptomatic treatment assisting in spontaneous closure of PDA as well as prophylactic treatment, which is based on pharmacological treatment on the first day of the life of the newborn [20]. Some studies suggest that the effectiveness of symptomatic treatment is comparable to the effects of prophylactic pharmacological treatment without risking pharmacological side effects in the newborn [21]. Currently, in newborns presenting with mild clinical symptoms, symptomatic therapy consisting of limiting fluid intake (80-150 ml/kg/day) [14, 22], administration of loop diuretics, adjustment of ventilation parameters to achieve controlled hypercapnia and metabolic alkalosis, application of CPAP ventilation or increasing PEEP, decreasing pulmonary flow, as well as increasing perfusion of peripheral tissues through application of CDAP [20], are the preferred treatments [5]. Furosemide as a prostaglandin agonist theoretically can cause maintenance of the patent arterial duct; however, the statistical significance between increased degree of symptomatic treatment failure and the application of furosemide has never been proven $[4,23]$. Numerous studies show a strict relationship between the degree of immaturity of the newborn and the increase in mortality risk as a result of PDA; 33\% mortality in newborns with a birth weight under $1500 \mathrm{~g}$ and almost half of newborns with a birth weight under $1000 \mathrm{~g}$. In newborns with PDA born before the $29^{\text {th }}$ week of gestation, mortality is eight times higher than in children born at the same gestational age without PDA [24]. The possibility of spontaneous closure of the PDA is different in selected groups of newborns and differs significantly in the cited studies. Some authors underline that in $70 \%$ of newborns born after the $28^{\text {th }}$ week of gestation, PDA closes spontaneously up to the $10^{\text {th }}$ day of life, and in newborns born before the $28^{\text {th }}$ week of gestation it closes spontaneously in $75 \%$ up to the $12^{\text {th }}$ month of life [21]. Koch claims that the PDA closes spontane- 
ously up to the $7^{\text {th }}$ day of life in $34 \%$ of newborns with low birth weight and born before the $28^{\text {th }}$ week of gestation [25], other researchers report a spontaneous closure of the PDA up to the $7^{\text {th }}$ day of life in $31 \%$ of preemies with a birth weight below $1000 \mathrm{~g}$ and in $67 \%$ with birth weight above $1000 \mathrm{~g}[20,26]$.

The optimal time of symptomatic treatment is from two to seven days after diagnosis of PDA with a USG examination [11]. The primary advantage of this method is the lack of exposure of the newborn to the side effects of drugs or interventional treatment $[27,28]$; however, we should be mindful of the fact that a delay in implementation of pharmacological treatment decreases the chances of the expected closure of the PDA. Additionally, preemies born before the $25^{\text {th }}$ week of gestation react less well to symptomatic therapy [28]. Symptomatic treatment in preemies with a birth weight over $1000 \mathrm{~g}$ with mild symptoms of PDA, and in whom there are no respiratory disturbances [12], usually gives satisfactory results [4]. In cases of symptoms of circulatory-respiratory insufficiency we should proceed to advanced pharmacological therapy [5].

\section{PHARMACOLOGICAL THERAPY}

Pharmacological therapy is an alternative in cases where symptomatic therapy has failed to yield the desired results [28]. Cyclooxygenase inhibitors such as indomethacin and ibuprofen, which have been approved for this purpose by the FDA (US Food and Drug Administration) are used as primary drugs to close the PDA [11, 27]. Paracetamol has been proposed as an alternative to indomethacin and ibuprofen due to its accessibility and low cost of treatment [28]. Numerous cases of successful closure of PDA in extreme preemies with the help of paracetamol have been documented; however, further studies are needed to assess the safety and efficacy of this option [12, 28-32].

Ibuprofen and indomethacin have identical efficacy in closure of PDA [11]. No significant difference has been found in the incidence of necrotising enterocolitis or development of neurological abnormalities in comparative analysis of both drugs [11]. It has been proven, however, that indomethacin is completely ineffective at closing PDA in term newborns and older children, and in preemies with extremely low birth weight the efficacy may be decreased as well [20].

Analysis comparing indomethacin and ibuprofen has indicated a comparable pharmacological efficacy for both drugs; the PDA very often closes after the second dose of the drug. Meta-analysis stresses the lower nephrotoxicity of ibuprofen, rarer episodes of oliguria, and its weaker peripheral vasoconstrictive properties when compared to indomethacin $[4,12,21,27,31]$. Consequently, the firstline drug in pharmacological therapy of PDA is ibuprofen [12]. Echocardiographic monitoring of pharmacological therapy is recommended in order to limit the exposure of the newborn to possible side effects of the drug $[25,26]$.

There are currently three main strategies of pharmacological therapy, which differ in time of induction of treatment, and the appropriate moment to begin pharmacological therapy is still a matter of some controversy $[4,10,21,26]$.

1) Prophylactic administration of COX inhibitors within 24 hours.

This method is significantly more effective in inducing vasoconstriction of the arterial duct when compared to delayed administration of drugs [10]. Indomethacin introduced 6-15 hours after birth in newborns born before $28^{\text {th }}$ week of gestation decreases the incidence of haemodynamically significant PDA and reduces the risk of potential later surgical intervention as well as reducing the risk of intraventricular haemorrhages $[4,10,21]$. According to some sources, ibuprofen does not significantly reduce mortality or the potential need for later surgical intervention.

2) Introduction of pharmacological therapy before the appearance of clinical symptoms.

3) Introduction of pharmacological therapy after the appearance of clinical symptoms.

Sensitivity to NSAIDs decreases with age. Postponement of pharmacological therapy may reduce the effectiveness of the therapy in this strategy [10,26, 27]. In cases of recurrence of PDA, pharmacological treatment may be reintroduced safely [22].

In preemies with PDA and hypotension, dopamine is used in the dosage below 10 micrograms $/ \mathrm{kg} / \mathrm{min}$, causing a rise in pulmonary pressure resulting in reduction in left-right shunting, which promotes spontaneous closure of the duct [32].

Among the disadvantages of pharmacological therapy are side-effects of the drugs as well as frequent recurrence of the PDA, which occurs in approximately 33\% of newborns with a birth weight below $1000 \mathrm{~g}$ and in $8 \%$ of newborns with a birth weight over $1500 \mathrm{~g}$ [5]. However, the benefits of pharmacological therapy in newborns have been confirmed in many respected studies showing a four-fold decrease in mortality rates in newborns born before the $28^{\text {th }}$ week of gestation [16]. Additionally, the majority of meta-analyses regarding pharmacological therapy highlight its role in reducing the necessity for later surgical intervention [4].

\section{CARDIOSURGICAL INTERVENTION}

The historical date of the first successful cardiosurgical operation closing a patent ductus arteriosus is 28 August 1938 when doctor Robert E. Gross successfully closed a PDA in a seven-year-old patient with heart failure at the Children's Hospital in Boston [33]. An indication for surgical intervention is a lack of technical possibilities to close the duct using minimally invasive percutaneous pro- 
cedures, which is an indication for classical thoracotomy in preemies and newborns [5], as well as the method of choice in cases with a very large diameter duct [2].

Surgical closure of the arterial duct is an extracardiac procedure and is carried out under general anaesthesia, most commonly using a left sided thoracotomy approach. Another possible approach is through a median sternotomy, especially in cases with complex heart defects, or a right sided thoracotomy in cases of right-sided aortic arch as well as in situations where other surgical procedures need to be carried out on the right side of the thorax simultaneously, i.e. Blalock-Hanlon procedure [18]. Closing the lumen of the duct is achieved through ligation and excision of the duct or through utilisation of vascular clips $[12,27]$. The efficacy of complete closure of the duct is high and reaches $94-100 \%$ with a perioperative mortality rate of $0-2 \%[2,34]$.

Over a span of decades, the surgical procedures used to close PDA have been modified and improved in order to minimise damage to the adjacent tissues. Mehmet et al. [35], introducing a lateral thoracotomy conserving the posterior zone of skeletal muscle, suggest clipping the duct rather than ligation as well as abandoning drainage of the thoracic cavity. The authors of the work report that this procedure leads to reduced postoperative in-hospital care duration, reduces the risk of perioperative complications, and at the same time reduces costs.

Complications of thoracotomy are rare, but when they occur they include: residual leakage, injury of the laryngeal nerve, injury of the phrenic nerve, pneumothorax, chylothorax, haemorrhage into the pleural cavity, postoperative haemorrhage, infection, periodic left ventricular dysfunction, bronchopulmonary dysplasia [2, 5, 12, 20, 27, 36] as well as (very rarely) accidental closure of the aorta or the left pulmonary artery $[2,5,18,27]$. Intercostal neuralgia and scoliosis of the thoracic segment of the vertebral column belong to the late complications of thoracotomy $[20,36]$.

Uncomplicated surgical intervention leads to a hospital stay of up to seven days. During hospitalisation the patient requires echocardiographic monitoring directly postoperatively as well as direct pre-discharge home.

In these cases the patient requires periodic cardiological follow-up; initially frequently until a year after the procedure when it becomes rarer, even up to several years apart. Special vigilance is necessary in development of posture due to the possibility of scoliosis of the thoracic segment of the vertebral column.

\section{THORACOSCOPIC SURGICAL CLOSURE}

The dynamic development of surgery of congenital heart defects has led to the advancement of minimally invasive surgical techniques. Over the past few years the video-assisted thoracoscopic surgery (VATS) minimally invasive technique has been adapted at an increasing num- ber of medical centres $[37,38]$. VATS was introduced and described initially by Jean Laborde in 1993 [39] and two years later by Redmond Burke [40]. The technique was implemented for the first time in Poland by Prof. Dariusz Patkowski from Wroclaw Medical University in 2012 operating on a child with Down's syndrome and oesophageal atresia.

Thoracoscopic closure of PDA is conducted under general anaesthesia in the prone position with the left side of the chest slightly elevated. Three ports are introduced using three or four 5-mm incisions, depending on the selected method (single or double handed). Small incisions are located in the posterior axillary line as well as posteriolaterally in the neighbourhood of the left scapula. Carbon dioxide is introduced into the pleural cavity through the ports in order to visualise the operative field, and a videoscope as well as surgical tools (forceps and retractor) are then inserted through the ports $[38,41-43]$. The camera allows the visualisation of the operative field and in doing so reduces the risk of damage to surrounding tissues. After preparation of the arterial duct, it is closed using one or two clips from the aortic side. Echocardiographic examination is carried out in the operating room to rule out leakage $[38,44]$. Carbon dioxide is then suctioned from the pleural cavity before the last suture is placed [43]. Patients are routinely extubated while still in the operating room [37, 39, 44, 45]. Drainage is inserted for a shorter time than associated with a classical procedure, or it may be omitted completely [46]. In order to exclude postoperative pneumothorax it is necessary to perform a chest X-ray [38]. The whole thoracoscopic procedure takes approximately 20 minutes, and the total in-hospital stay is one to three days postoperatively $[37,42,43]$.

VATS is usually carried out in an operating room if an emergency thoracotomy arises; however, there is also the possibility of carrying out the procedure in smaller treatment rooms, or in the case of newborns in the neonatal intensive care unit [38].

Contraindications for VATS are: large diameter of the duct (above 8 or $9 \mathrm{~mm}$ ), short, wide, or windowed PDA, calcification of the duct, severely scarred pleura, earlier thoracotomy, persistent infection, or coexisting aneurysm of the PDA [37, 38, 41, 42]. Complications arising from thoracoscopy are rare but may include: injury to the recurrent laryngeal nerve, injury to the phrenic nerve, pneumothorax, residual leakage, chylothorax, and accidental closure of another vessel [37, 38].

In comparative meta-analyses many authors note frequent injury to the laryngeal nerve when compared to thoracotomy; however, the injuries are also more frequently transient in nature [44]. Mortality due to VATS is nearly zero, which confirms its safety for use in all age groups.

In cases of duct closure in older children and adults, VATS is an alternative treatment method to percutaneous closure of the duct $[42,47]$. The necessity for cardio- 
logical follow-up in uncomplicated cases of thoracoscopic closure of PDA is short term. In most cases the patient requires no further follow-up a year after the procedure.

\section{PERCUTANEOUS CLOSURE OF PDA - CARDIOLOGICAL TREATMENT}

Significant technological advances in medicine have allowed development of percutaneous operative methods. The technique of percutaneous closing of patent ductus arteriosus has its roots in East Germany in 1967 when doctor Werner Portsmann with his surgical team closed a PDA in a 17-year-old patient with the help of a plug made from polyvinyl sponge [34, 48]. Several years later in 1976, William Rashkind introduced a new technique for PDA closure using a so-called "double umbrella" [49]. In Poland, this method was used until 1999 because procedures carried out using Raskind's double umbrella method were burdened with residual leakage [50].

Currently the method in everyday use utilises coils, first implemented in PDA closure in 1992 by the team of Cambiera and Moore [51], as well as clasps, called Amplatz implant (ADO) [34]. The main limiting factor in percutaneous closure of the patent ductus arteriosus is the minimal body mass of the patient. According to various sources, body mass should be above five kilograms, which is why this method is used in older infants, children, and adults $[2,14,24,52,53]$. The choice of device is based not only on body mass and age of the patient but also on the diameter of the ampulla and the morphology of the duct $[14,54]$. An indication to closing the arterial duct with a coil is diameter below $2-2.5 \mathrm{~mm}$ in the narrowest place $[34,55,56]$. In cases of closing PDA with diameter below $1.5 \mathrm{~mm}$ a single coil is usually enough. Arterial ducts with a diameter of over $1.5 \mathrm{~mm}$ require multiple coils according to certain authors, which raises the need to take into account the increased risk of residual leakage. Researchers in many available studies underline the significant risk of implant shifting as well as other complications arising from the usage of multiple coils. As a result, placement of multiple coils should no longer be practiced, and due to the gathered experience and development of technology Amplatzer implant should now be used for closure of PDAs with a diameter over $1.5 \mathrm{~mm}$ in their narrowest part.

The Amplatzer implant is a self-expanding construction in the shape of a mushroom, made from a Nitinil wire mesh with polyester elements that are capable of free movement and correct placement during the procedure $[2,14]$. Indications for use of $\mathrm{ADO}$ and its derivatives are medium sized and larger arterial ducts, whose diameter in the narrowest segment is larger than $2.5 \mathrm{~mm}$ (>2 $\mathrm{mm}$ ) $[2,34,55,56]$. Currently these are the most widespread devices used in surgical treatment of PDA [34], however, due to the significantly higher costs of Amplatzer implant, treatment with multiple coils in cases of larger PDAs still occurs sporadically.
The complications of percutaneous closure of PDA are residual leakage, haemorrhage and trauma of large vessels, exposure to X-ray radiation, and risk associate with the toxicity of contrast medium. Additionally, due to mechanical irritation of the area with the tools, contraction of the tunica media of the arterial duct may occur [34], leading to misinterpretation of the actual size of the duct and improper clasp selection, which may in turn lead to persistent leakage or displacement of the coil or clasp. Late complications may also occur, such as coarctation of the aorta and stenosis of the left pulmonary artery [57]. The risk of complications increases with the diameter of the patent duct. Percutaneous closure of PDA is characterised by a mortality of close to zero, quick convalescence, and short hospital stay. The lower invasiveness, fewer complications, and comparable efficacy indicate the superiority of percutaneous closure of PDA over traditional surgical therapeutic techniques. Small patients, after successful, uncomplicated closure of a PDA require sporadic cardiological monitoring. The first echocardiographic exam takes place directly after the placement of percutaneous closure, and additional consultations are indicated for one month after the procedure as well as for six months and one year thereafter. Further cardiological care is sporadic. In order for percutaneous PDA closure methods to become the method of choice for the youngest children, it is necessary to miniaturise the equipment, which will facilitate manipulation of the catheter and prevent perioperative trauma, arrhythmias, and haemodynamic instability [58].

\section{SUMMARY}

Based on analysis of the presented methods of PDA closure, currently available and performed, it is impossible to pick a single, best method. Each of the described methods has its advantages as well as drawbacks. Choosing the method should be based on many diverse qualifying criteria: the haemodynamic significance of the PDA, the overall health of the patient, their age and body mass, minimal invasiveness, and the minimisation of peri- and post-operative trauma. Symptomatic treatment is limited to newborns in stable condition with a haemodynamically significant PDA; it is not available to older children due to the ineffectiveness of this method in that cohort. The primary advantage of this method is the exclusion of the possibility of side effects from pharmacological or invasive treatment. Meanwhile, in cases where symptoms of cardiorespiratory insufficiency are present, advanced pharmacological treatment should be implemented using COX inhibitors. In available meta-analyses the side effects of ibuprofen are described as significantly lower when compared to indomethacin as well as the lower risk of spontaneous reopening of the PDA at a later date [26]. The time of start of treatment with these drugs varies significantly in the data sources, from prophylactically to 
24 hours after birth, based on whether the source says to start treatment before clinical symptoms appear or after.

In the past, the method of choice for closing haemodynamically significant PDA was cardiac surgery. Presently, thanks to the development of techniques, less traumatic methods of PDA closure exist, such as minimally invasive surgical thoracoscopic closure VATS as well as percutaneous closure using coils or Amplatzer implant. The main drawbacks of percutaneous closure of the PDA are the body mass of the patient (which, according to various sources, should be over five kilograms) as well as availability of access to a haemodynamic procedure room and use of X-ray technology for visualisation of the field. The smaller the body mass of the child and the larger the diameter of the PDA, the greater the risk of complications.

The latest method of those presented is thoracoscopic closure of the PDA, which currently appears to be the most universal method, without limitations regarding the body mass, age, or general condition of the patient and can be performed in an operating theatre as well as in a procedure room. Complications arising from thoracoscopy are rare and few.

The limitations of this treatment method as well as the percutaneous technique are: large diameter of the duct, calcification of the duct, structural defects of the pleura, earlier thoracotomy, persistent infection, or simultaneous aneurysm of the PDA. Perioperative mortality in the presented methods is close to zero. The highest procedural effectiveness in closing PDA belongs to surgical closure, but with percutaneous and thoracoscopic methods of PDA closure very close behind.

The decision regarding the method of closure of PDA should be based on the best current medical knowledge, the experience and expertise of the cardiac surgeon, and the procedural capabilities of the hospital in which the procedure takes place.

\section{DISCLOSURE}

The authors declare no conflict of interest.

\section{REFERENCES}

1. Michelakis ED, Rebeyka I, Wu X i wsp. O2 sensing in the human ductus arteriosus: Regulation of voltage-gated $\mathrm{K}+$ channels in smooth muscle cells by a mitochondrial redox sensor. Circ Res 2002; 91: 478-486.

2. Schneider DJ, Moore JW. Patent ductus arteriosus. Circulation 2006; 114: 1873-1882.

3. Żyła-Frycz M. Wady przewodozależne. W: Kardiochirurgia dziecięca. Skalski JH, Religa Z (eds.). Wydawnictwo Naukowe Śląsk, Katowice 2003; 327-338.

4. Mehtr S, Younoszai A, Pietz J, Achanti B. Pharmacological closure of the patent ductus arteriosus. Images Paediatr Cardiol 2003; 14: $1-15$

5. Jędrzejek M, Sarbinowska J, Wiślińska K, Błaż W. Patent ductus arteriosus - not only a paediatric issue. Pediatr Med Rodz 2014; 10: 291-305.
6. Matsui H, McCarthy K, Ho S. Morphology of the patent arterial duct: features relevant to treatment. Images Paediatr Cardiol 2008; 10: 27-38.

7. Van Overmeire B, Chemtob S. The pharmacologic closure of the patent ductus arteriosus. Semin Fetal Neonatal Med 2005; 10: 177-184.

8. Khositseth A, Nuntnarumit P, Chongkongkiat P. Echocardiographic parameters of patent ductus arteriosus in preterm infants. Indian Pediatr 2011; 48: 773-778.

9. Philips JB. Pathophysiology, clinical manifestations, and diagnosis of patent ductus arteriosus in premature infants. In: UpToDate. Garcia-Prats JA, Fulton DR (ed.).

10. Hermes-DeSantis ER, Clyman RI. Patent ductus arteriosus: pathophysiology and management. J Perinatol 2006; 26 Suppl 1: S14-18; discussion S22-S23.

11. Sekar KC, Corff KE. Treatment of patent ductus arteriosus: indomethacin or ibuprofen? J Perinatol 2008; 28 Suppl 1: S60-S62.

12. Sinha B. Controversies in Management of Patent Ductus Arterious in the Preterm Infant. J Pulm Respir Med 2013; S13: 007; doi: 10.4172/2161-105X.S13-007.

13. Mazur W, Siegel MJ, Miszalski-Jamka T, et al. CT Atlas of adult congenital heart disease. Springer Science \& Business Media, London 2013.

14. Doyle T, Kavanaugh-McHugh A, Soslow J, et al. Management of patent ductus arteriosus. In: UpToDate. Triedman JK, Connolly HM (eds.) (Accessed in 2016).

15. Rao PS. Percutaneous closure of patent ductus arteriosus - current status. J Invasive Cardiol 2011; 23: 517-520.

16. Moss and Adams' heart disease in infants, children, and adolescents. Allen HD, Driscoll DJ, Shaddy RE, et al. (eds.). Lippincott Williams \& Wilkins, Philadelphia 2013.

17. Fortescue EB, Lock JE, Galvin T, et al. To close or not to close: the very small patent ductus arteriosus. Congenit Heart Dis 2010; 5: 354-365.

18. Wojtalik M, Mrówczyński W, Skalski JH. Przetrwały przewód tętniczy. In: Kardiochirurgia dziecięca. Skalski JH, Religa Z (eds.). Wydawnictwo Naukowe Śląsk, Katowice 2003; 327-338.

19. Aleszewicz-Baranowska J, Komorowska W. Podstawy diagnostyki kardiologicznej u dzieci. Forum Med Rodz 2007; 1: 242-249.

20. Hamrick SE, Hansmann G. Patent ductus arteriosus of the preterm infant. Pediatrics 2010; 125: 1020-1030.

21. Vanhaesebrouck S, Zonnenberg I, Vandervoort P, et al. Conservative treatment for patent ductus arteriosus in the preterm. Arch Dis Child Fetal Neonatal Ed 2007; 92: F244-F247.

22. Zalecenia Polskiego Towarzystwa Neonatologicznego: Standardy opieki medycznej nad noworodkiem w Polsce. Borszewska-Kornacka MK (ed.). Media-Press, Warszawa 2017.

23. Controversies around treatment of the open duct. Springer Science \& Business Media 2011; 200. Available from: https://books.google. com/books?id=m1W2UCuVFbwC\&pgis $=1$

24. Zahn EM, Nevin P, Simmons C, Garg R. A novel technique for transcatheter patent ductus arteriosus closure in extremely preterm infants using commercially available technology. Catheter Cardiovasc Interv 2015; 85: 240-248.

25. Forbes TJ, Harahsheh A, Rodriguez-Cruz E, et al. Angiographic and Hemodynamic Predictors for Successful Outcome of Transcatheter Occlusion of Patent Ductus Arteriosus in Infants Less Than 8 Kilograms. Catheter Cardiovasc Interv 2004; 61: 117-122.

26. Evans N. Current controversies in the diagnosis and treatment of patent ductus arteriosus in preterm infants. Adv Neonatal Care 2003; 3: 168-177.

27. Dice JE, Bhatia J. Patent ductus arteriosus: an overview. J Pediatr Pharmacol Ther 2007; 12: 138-146.

28. Ibrahim TK, Haium AA, Chandran S, et al. Current controversies in the management of patent ductus arteriosus in preterm infants. Indian Pediatr 2014; 51: 289-294. 
29. Sakhalkar VS, Merchant RH. Therapy of symptomatic patent ductus arteriosus in preterms using mefenemic acid and indomethacin. Indian Pediatr 1992; 29: 313-318.

30. Park HJ, Jung YS, Kim NS, et al. A Comparative study of the effects of intravenous indomethacin and oral mefenamic acid in the treatment of premature infants with patent ductus arteriosus. Korean J Pediatr 2001; 44: 32-39.

31. Abdel-Hady H, Nasef N, et al. Patent Ductus Arteriosus in Preterm Infants: Do We Have the Right Answers? Hindawi Publishing Corporation, BioMed Research International 2013; doi: http://dx.doi. org/10.1155/2013/676192.

32. Bouissou A, Rakza T, Klosowski S, et al. Hypotension in Preterm Infants with Significant Patent Ductus Arteriosus: Effects of Dopamine. J Pediatr 2008; 153: 790-794.

33. Kaemmerer H, Meisner H, Hess J, Perloff J. Surgical treatment of Patent Ductus Arteriosus: A new historical perspective. Am J Cardiol 2004; 94: 1153-1154.

34. Baruteau A-E, Hascoët S, Baruteau J, et al. Transcatheter closure of patent ductus arteriosus: past, present and future. Arch Cardiovasc Dis 2014; 107: 122-132.

35. Taşar M, Yaman ND, Eyileten Z, et al. Surgery for patent ductus arteriosus in infants with very low birth weight. Cardiovasc Surg Int 2015; 2: 54-57.

36. Chen H, Weng G, Chen Z, et al. Comparison of posterolateral thoracotomy and video-assisted thoracoscopic clipping for the treatment of patent ductus arteriosus in neonates and infants. Pediatric Cardiology 2011; 32: 386-390.

37. Villa E, Eynden F Vanden, et al. Paediatric video-assisted thoracoscopic clipping of patent ductus arteriosus: Experience in more than 700 cases. Eur J Cardiothorac Surg 2004; 25: 387-393.

38. Jacobs JP, Giroud JM, Quintessenza JA, et al. The Modern Approach to Patent Ductus Arteriosus Treatment: Complementary Roles of Video-Assisted Thoracoscopic Surgery and Interventional Cardiology Coil Occlusion. Ann Thorac Surg 2003; 76: 1421-1428.

39. Laborde F, Noirhomme P, Karam J, et al. A new video-assisted thoracoscopic surgical technique for interruption of patient ductus arteriosus in infants and children. J Thorac Cardiovasc Surg 1993; 105: 278-280.

40. Burke RP, Jacobs JP, Cheng W, et al. Video-assisted thoracoscopic surgery for patent ductus arteriosus in low birth weight neonates and infants. Pediatrics 1999; 104: 227-230.

41. Nezafati MH, Mahmoodi E, Hashemian SH, et al. Video-assisted thoracoscopic surgical (VATS) closure of Patent Ductus Arteriosus: Report of three-hundred cases. Heart Surg Forum 2002; 5: 57-59.

42. Dutta S, Mihailovic A, Benson L, et al. Thoracoscopic ligation versus coil occlusion for patent ductus arteriosus: A matched cohort study of outcomes and cost. Surg Endosc Other Interv Tech 2008; 22: 1643-1648.

43. Kołtowski P, Patkowski D, Adamus J, et al. Thoracoscopic closure of patent ductus arteriosus in 2 premature infants weighing 700 and 800 g. Polish J Cardio-Thoracic Surg 2012; 4: 428-430.

44. Vanamo K, Berg E, Kokki H, et al. Video-assisted thoracoscopic versus open surgery for persistent ductus arteriosus. J Pediatr Surg 2006; 41: 1226-1229.

45. Vida VL, Rubino M, Bottio T, et al. Thoracoscopic closure of the patent arterial duct. Cardiol Young 2004; 14: 164-167.

46. Nezafati MH, Soltani G, Vedadian A. Video-assisted ductal closure with new modifications: minimally invasive, maximally effective, 1,300 cases. Ann Thorac Surg 2007; 84: 1343-1348.

47. Das MB, Kapoor L, Moulick A, et al. Video-assisted thoracoscopic surgery for closure of patent ductus arteriosus in children. Indian Heart J 1997; 49: 300-302.

48. Yarrabolu RT. Transcatheter closure of patent ductus arteriosus. Pediatr Ther 2012; 01(S5).
49. Rashkind WJ, Mullins CE, Hellenbrand WE, et al. Nonsurgical closure of patent ductus arteriosus: clinical application of the Rashkind PDA Occluder System. Circulation1987; 75: 583-592.

50. Szczeklik A, Tendera M. Kardiologia. Wydawnictwo Medycyna Praktyczna, Kraków 2009; 589.

51. Cambier PA, Kirby WC, Wortham DC, et al. Percutaneous closure of the small $(<2.5 \mathrm{~mm})$ patent ductus arteriosus using coil embolization. Am J Cardiol 1992; 69: 815-816.

52. Dimas VV, Takao C, Ing FF, et al. Outcomes of transcatheter occlusion of patent ductus arteriosus in infants weighing $<6 \mathrm{~kg}$. JACC Cardiovasc Interv 2010; 3: 1295-1299.

53. Kusa J, Raś M, Cześniewicz P, et al. Less invasive percutaneous closure of persistent arterial duct in children below 10 kilos. Postep Kardiol Inter 2013; 9: 132-135.

54. Francis E, Singhi AK, Lakshmivenkateshaiah S, et al. Transcatheter occlusion of patent ductus arteriosus in pre-term infants. JACC Cardiovasc Interv 2010; 3:550-555.

55. Ali SH, Abdalla SE. Percutaneous transcatheter closure of patent ductus arteriosus: Initial experience of Sohag University. Egypt Hear J 2014; 66: 143-147.

56. Azhar AS, Abd El-Azim AA, Habib HS. Transcatheter closure of patent ductus arteriosus: evaluating the effect of the learning curve on the outcome. Ann Pediatr Cardiol 2009; 2: 36-40.

57. Doshi AR, Rao PS. Development of aortic coarctation following device closure of patent ductus arteriosus. J Invasive Cardiol 2013; 25: 464-467.

58. Park YA, Kim NK, Park J, et al. Clinical outcome of transcatheter closure of patent ductus arteriosus in small children weighing $10 \mathrm{~kg}$ or less. Korean J Pediatr 2010; 53: 1012-1027. 